\title{
Photochemical mineralization of di-n-butyl phthalate with $\mathrm{H}_{2} \mathrm{O}_{2} / \mathrm{Fe}^{3+}$
}

\author{
Chyow-San Chiou ${ }^{\mathrm{a}, *}$, Yi-Hung Chen ${ }^{\mathrm{b}}$, Chang-Tang Chang ${ }^{\mathrm{a}}$, \\ Ching-Yuan Chang ${ }^{\mathrm{c}}$, Je-Lueng Shie ${ }^{\mathrm{a}}$, Yuan-Shan $\mathrm{Li}^{\mathrm{a}}$ \\ ${ }^{a}$ Department of Environmental Engineering, National I-Lan University, 1, Section 1, Shen-Lung Road, I-Lan 260, Taiwan \\ ${ }^{\mathrm{b}}$ Department of Chemical and Material Engineering, National Kaohsiung University of Applied Sciences, Kaohsiung, Taiwan \\ ${ }^{\mathrm{c}}$ Graduate Institute of Environmental Engineering, National Taiwan University, Taipei, Taiwan \\ Received 21 July 2005; received in revised form 15 November 2005; accepted 28 November 2005 \\ Available online 6 January 2006
}

\begin{abstract}
This study evaluated the performance of photo-Fenton reaction initiated by the UV irradiation with $\mathrm{H}_{2} \mathrm{O}_{2} / \mathrm{Fe}^{3+}$, denoted as $\mathrm{UV} / \mathrm{H}_{2} \mathrm{O}_{2} / \mathrm{Fe}^{3+}$, to decompose di- $n$-butyl phthalate (DBP) in the aqueous solution. The concentration of total organic carbon (TOC) was chosen as a mineralization index of the decomposition of DBP by the $\mathrm{UV} / \mathrm{H}_{2} \mathrm{O}_{2} / \mathrm{Fe}^{3+}$ process. A second-order kinetic model with respect to TOC was adequately adopted to represent the mineralization of DBP by the $\mathrm{UV} / \mathrm{H}_{2} \mathrm{O}_{2} / \mathrm{Fe}^{3+}$ process. The experimental results of this study suggested that the dosages with $4.74 \times 10^{-5} \mathrm{~mol} \mathrm{~min}^{-1} \mathrm{~L}^{-1} \mathrm{H}_{2} \mathrm{O}_{2}$ and initial $\mathrm{Fe}^{3+}$ loading concentration of $4.50 \times 10^{-4} \mathrm{~mol} \mathrm{~L}^{-1}$ in the solution at $\mathrm{pH} 3.0 \mathrm{with} 120 \mu \mathrm{W} \mathrm{cm}^{-2} \mathrm{UV}^{-}$ $(312 \mathrm{~nm})$ provided the optimal operation conditions for the mineralization of DBP $\left(5 \mathrm{mg} \mathrm{L}^{-1}\right)$ yielding a $92.4 \%$ mineralization efficiency at 90 min reaction time.
\end{abstract}

(C) 2005 Elsevier B.V. All rights reserved.

Keywords: Photo-Fenton; Mineralization; $\mathrm{UV} / \mathrm{H}_{2} \mathrm{O}_{2} / \mathrm{Fe}^{3+}$; Di- $n$-butyl phthalate

\section{Introduction}

Phthalic acid esters (PAEs) are widely used as plasticizers in different resins, especially PVC resin [1], and important additives in special paints and adhensives. The United States Environmental Protection Agency (USEPA) [2] and some of its international counterparts have classified the most common PAEs as priority pollutants and as endocrine-disrupting compounds.

PAEs, especially di- $n$-butyl phthalate (DBP) [3], have become widespread in the environment as they have been found in sediments, waters and soils [4,5], as a result of their low water solubility and high octanol/water partition coefficients, PAEs tend to accumulate in the soil or sediment and in the biota living in the phthalate containing waters. DBP also is a rather stable compound in the natural environment, and the toxic properties of which are even more important with the consideration of its high bioaccumulation rate in different organisms [4]. Huang et al. [6] found that some of PAEs, such as DBP and DEHP

\footnotetext{
* Corresponding author. Tel.: +88639357400x747; fax: +88639359674.

E-mail address: chiou33@ms7.hinet.net (C.-S. Chiou).
}

(di-2-ethylhexyl phthalate), were the main refractory organic compounds in municipal wastewater. In conventional activated sludge plants, a large number of these organic pollutants are difficult to be degraded when passed through the treatment facilities.

The application of Fenton reaction to produce hydroxyl radicals for decomposing organic pollutants has attracted extensive attention [7]. It has been successfully applied to degrade the aromatic compounds [8-10]. Through the function of the agent of Fenton reaction, which is a mixture of $\mathrm{H}_{2} \mathrm{O}_{2}$ with iron salts, can generate the strong oxidative hydroxyl radicals, ${ }^{\circ} \mathrm{OH}$ according to the following reactions [11]:

$$
\begin{aligned}
& \mathrm{Fe}^{2+}+\mathrm{H}_{2} \mathrm{O}_{2} \rightarrow \mathrm{Fe}^{3+}+\bullet \mathrm{OH}+\mathrm{OH}^{-}, \quad k_{1}=76 \mathrm{M}^{-1} \mathrm{~s}^{-1} \\
& \mathrm{Fe}^{3+}+\mathrm{H}_{2} \mathrm{O}_{2} \rightarrow \mathrm{Fe}^{2+}+\mathrm{HO}_{2} \bullet+\mathrm{H}^{+}, \quad k_{2}=0.02 \mathrm{M}^{-1} \mathrm{~s}^{-1}
\end{aligned}
$$

The main short comes of Fenton reaction are that $\mathrm{Fe}^{2+}$ and $\mathrm{H}_{2} \mathrm{O}_{2}$ must be added continuously to keep the reaction proceeding and produced the large volume of wasted iron hydroxide sludge. In order to overcome the sludge problem and enhance the Fenton reactions, a photo-Fenton process $[12,13]$ was devel- 
oped by introducing ultraviolet (UV) light to a Fenton process. By applying UV light, $\mathrm{Fe}^{2+}$ can be regenerated via the following photo-reactions [14]:

$\mathrm{Fe}(\mathrm{OH})^{2+}+h v \rightarrow \mathrm{Fe}^{2+}+{ }^{\bullet} \mathrm{OH}$

$\mathrm{Fe}(\mathrm{OH})_{6}^{3+}+h v \rightarrow \mathrm{Fe}^{2+}+\cdot \mathrm{OH}+\mathrm{H}^{+}$

Reduction of $\mathrm{Fe}^{3+}$ to $\mathrm{Fe}^{2+}$ is advantageous to proceed the Fenton reaction repeatedly without continuously adding $\mathrm{Fe}^{2+}$, and reduce the amount of iron hydroxide sludge. Furthermore, the reaction mechanism of Eqs. (3) and (4) also generate the strong oxidant, ${ }^{\bullet} \mathrm{OH}$ to mineralize the target organic compounds. Moreover, a hydrogen peroxide can produce two hydroxyl radicals initiated by UV light, according to Eq. (5):

$\mathrm{H}_{2} \mathrm{O}_{2}+h v \rightarrow 2^{\bullet} \mathrm{OH}$

Among these routes, Eqs. (3)-(5) facilitate the formation of hydroxyl radicals and promote the decomposition rates of organic compounds. Many previous studies had shown that the decomposition of various refractory organic compounds [15-20] via the photo-Fenton process had been proven to be very effective.

The present study assessed the function of UV light on the enhancing $\mathrm{H}_{2} \mathrm{O}_{2} / \mathrm{Fe}^{3+}$, denoted as $\mathrm{UV} / \mathrm{H}_{2} \mathrm{O}_{2} / \mathrm{Fe}^{3+}$ process, to mineralize DBP. The concentration of total organic carbon (TOC) was chosen as a mineralization index of the decomposition of DBP by this $\mathrm{UV} / \mathrm{H}_{2} \mathrm{O}_{2} / \mathrm{Fe}^{3+}$ process. The effects of $\mathrm{pH}$ value, $\mathrm{UV}$ light intensity, $\mathrm{H}_{2} \mathrm{O}_{2}$ dosage rate and $\mathrm{Fe}^{3+}$ concentration on the mineralization of DBP were examined. The related kinetic equations were also established based on the observed experimental results.

\section{Materials and methods}

Di- $n$-butyl phthalate, DBP $\left(\mathrm{C}_{16} \mathrm{H}_{22} \mathrm{O}_{4}, \mathrm{MW}=278\right)$, with high quality was purchased from Acros Organics (Belgium) and used without any further purification. Hydrogen peroxide (35\%) and ferric nitrate were supplied by Shimakyu Co. (Japan) and Merck, respectively. The TOC of sample was analyzed by a TOC analyzer (Tekmar Dohrmann Phoenix 8000). This instrument utilizes the UV-persulfate technique to convert the organic carbon into carbon dioxide $\left(\mathrm{CO}_{2}\right)$ analyzed by an infrared $\mathrm{CO}_{2}$ analyzer and calibrated with the potassium hydrogen phthalate. The relative standard deviation of TOC analyses of DBP samples with triple measurements are below $5 \%$.

Batch experiments of the oxidation process were conducted in a $2 \mathrm{~L}$ well-mixed round-bottle glass flask with water jacket (Fig. 1). The UV irradiation source was two $8 \mathrm{~W}$ lamps encased in a quartz tube with wavelengths of $312 \mathrm{~nm}$. UVX Radiometer (UVP Inc., USA) was employed for the determination of UV light intensity. The UV intensity of one $8 \mathrm{~W}$ UV lamp at $312 \mathrm{~nm}$ is $60 \mu \mathrm{W} \mathrm{cm}{ }^{-2}$. A variable speed motor connected to a stainless steel shaft provided the mixing medium. A pH controller was used to control $\mathrm{pH}$ value of solution by adding $0.1 \mathrm{M} \mathrm{HNO}_{3}$ or $\mathrm{NaOH}$ solution into the reactor. Hydrogen peroxide was supplied by a syringe pump with a constant feed rate.

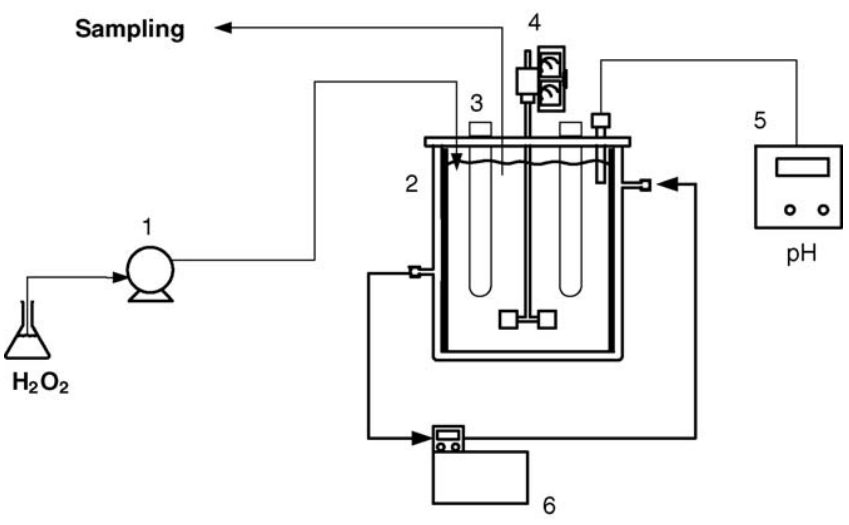

Fig. 1. The experimental apparatus sketch. Components: (1) syringe pump; (2) reaction vessel; (3) UV lamp; (4) stirrer; (5) pH meter; (6) thermostate.

The effect of $\mathrm{pH}$ value of solution on the system performance was studied at various $\mathrm{pH}$ values of 2.0, 2.5, 3.0, 3.5 and 4.0 with the constant dosage rate of $\mathrm{H}_{2} \mathrm{O}_{2}\left(\mathrm{dC}_{\mathrm{H}_{2} \mathrm{O}_{2}} / \mathrm{d} t\right)$ at $3.15 \times 10^{-5} \mathrm{~mol} \mathrm{~min}^{-1} \mathrm{~L}^{-1}$ and the initial loading concentrations of $\mathrm{Fe}^{3+}\left(C_{\mathrm{Fe}^{3+}, 0}\right)$ of $3.60 \times 10^{-4} \mathrm{~mol} \mathrm{~L}^{-1}$ and DBP of $5 \mathrm{mg} \mathrm{L}^{-1}$, respectively. The influence of the UV irradiation on the system performance was evaluated with and without $\mathrm{UV}$ at $\mathrm{pH}$ value of 3.0. The study of the effect of $C_{\mathrm{Fe}^{3+}, 0}$ was evaluated at various initial concentrations of $9.01 \times 10^{-5}, 1.80 \times 10^{-4}, 2.70 \times 10^{-4}, 3.60 \times 10^{-4}$, $4.50 \times 10^{-4}$ and $5.41 \times 10^{-4} \mathrm{~mol} \mathrm{~L}^{-1}$ with $120 \mu \mathrm{W} \mathrm{cm}{ }^{-2} \mathrm{UV}$ intensity $(312 \mathrm{~nm}), 3.15 \times 10^{-5} \mathrm{~mol} \mathrm{~min}^{-1} \mathrm{~L}^{-1}$ hydrogen peroxide and $5 \mathrm{mg} \mathrm{L}^{-1} \mathrm{DBP}$ at $\mathrm{pH}$ value of 3.0. The effect of hydrogen peroxide was examined by dosing hydrogen peroxide at various dosage rates $\left(3.95 \times 10^{-6}, 7.90 \times 10^{-6}, 1.58 \times 10^{-5}\right.$, $3.15 \times 10^{-5}, 4.74 \times 10^{-5}$ and $\left.5.54 \times 10^{-5} \mathrm{~mol} \mathrm{~min}^{-1} \mathrm{~L}^{-1}\right)$ into the reactor. The temperature for the all experiments was maintained at $298 \mathrm{~K}$.

\section{Results and discussion}

\subsection{Effects of pH value}

The $\mathrm{pH}$ value was reported as a parameter that affects the performance of the Fenton reaction [21], and the species concentration of $\mathrm{Fe}^{3+}$-hydroxyl complex in aqueous solution. Therefore, the effect of $\mathrm{pH}$ value on the destruction of DBP via the photo-Fenton reaction was investigated. As shown in Fig. 2, the mineralization efficiency of $\mathrm{TOC}_{\mathrm{DBP}}$, $\eta_{\text {TOC,DBP }}=\left(\mathrm{TOC}_{0}-\mathrm{TOC}\right) / \mathrm{TOC}_{0}$, increases with the decrease of $\mathrm{pH}$ to $\mathrm{pH}$ value of 3.0, but would decrease with the further decreasing of the $\mathrm{pH}$ values. Previous studies on the Fenton process $[22,23]$ reported that the optimal $\mathrm{pH}$ value condition for a Fenton reaction is at $\mathrm{pH} 3$, suggesting that $\mathrm{H}^{+}$in the solution at low $\mathrm{pH}$ values would consume ${ }^{\bullet} \mathrm{OH}$ via Eq. (6) and form $\mathrm{H}_{2} \mathrm{O}$ [14]:

$\bullet \mathrm{OH}+\mathrm{H}^{+}+\mathrm{e}^{-} \rightarrow \mathrm{H}_{2} \mathrm{O}, \quad k=7 \times 10^{-9} \mathrm{M}^{-1} \mathrm{~s}^{-1}$

Hence, the excess $\mathrm{H}^{+}$under low $\mathrm{pH}$ condition, $\mathrm{pH}<3$, decreases the decomposition performance of the target organic com- 


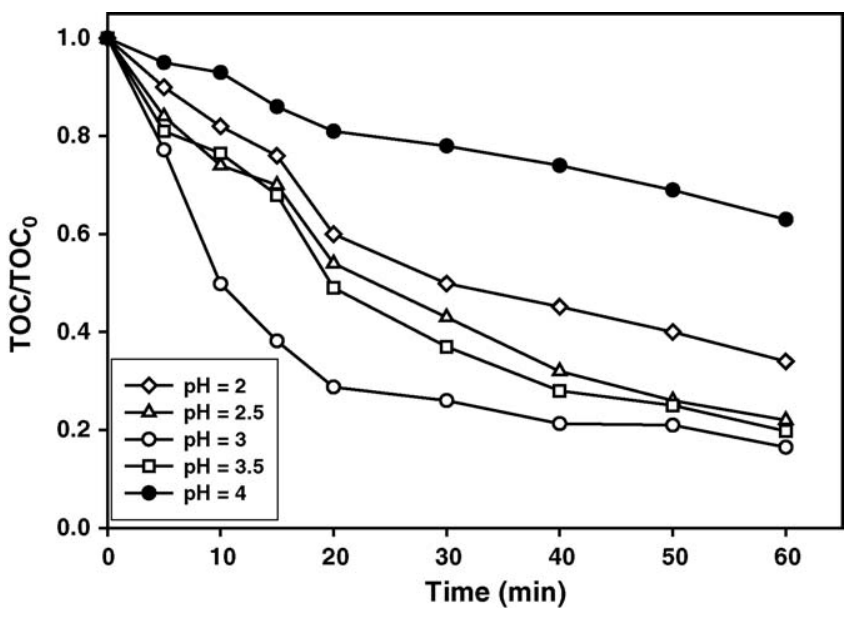

Fig. 2. Dependence of mineralization of $\mathrm{DBP}$ on time at various $\mathrm{pH}$ values adjusted by $\mathrm{HNO}_{3}$. Experimental conditions: initial concentrations of DBP $\left(C_{\mathrm{DBP} O}\right)=5 \mathrm{mg} \mathrm{L}^{-1}$, and initial concentrations of $\mathrm{Fe}^{3+}$ $\left(C_{\mathrm{Fe}^{3+}, 0}\right)=3.60 \times 10^{-4} \mathrm{~mol} \mathrm{~L}^{-1}$, dosing rate of $\mathrm{H}_{2} \mathrm{O}_{2}\left(\mathrm{dC}_{\mathrm{H}_{2} \mathrm{O}_{2}} / \mathrm{d} t\right)=3.15 \times$ $10^{-5} \mathrm{~mol} \mathrm{~min}^{-1} \mathrm{~L}^{-1}$, UV intensity $\left(\lambda_{312}\right)=120 \mu \mathrm{W} \mathrm{cm}{ }^{-2}$ and $T=298 \mathrm{~K}$.

pound. Moreover, $\mathrm{Fe}(\mathrm{OH})^{2+}$ is the dominant species among the $\mathrm{Fe}^{3+}$-hydroxyl complex in the aqueous solution from $\mathrm{pH} 2.5$ to 5 , and the highest quantity of $\mathrm{Fe}(\mathrm{OH})^{2+}$ is obtained at $\mathrm{pH} 4$ [14]. The concentration of $\mathrm{Fe}(\mathrm{OH})^{2+}$ decreases with $\mathrm{pH}$ values beyond or below 4 , and the lower quantity of $\mathrm{Fe}(\mathrm{OH})^{2+}$ results lower concentration of $\mathrm{Fe}^{2+}$ and ${ }^{\bullet} \mathrm{OH}$ via Eq. (3). As $\mathrm{pH}<3$, the concentration of $\mathrm{Fe}(\mathrm{OH})^{2+}$ decreased with decreasing $\mathrm{pH}$ value of aqueous solution which subsequently contributed poor $\eta_{\text {TOC,DBP. }}$

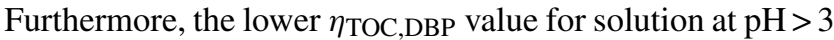
might be due to that the oxidation potential of ${ }^{\bullet} \mathrm{OH}$ was decreased with increasing $\mathrm{pH}$ [24], and the formation of the precipitation of iron hydroxide $(\mathrm{pH}>4)$. Thus, the optimal $\mathrm{pH}$ value for the effective mineralization of DBP was found to be 3.0 , and the $\mathrm{pH}$ value of solution was maintained at 3.0 for the following experiments.

\subsection{Mineralization efficiency of DBP under various conditions}

The wavelength of radiation is also an important parameter for the production of $\mathrm{Fe}^{2+}$ and hydroxyl radical from the $\mathrm{Fe}^{3+}$-hydroxyl complex in aqueous solution via the photolytic reaction $[14,25,26]$. $\mathrm{As} \mathrm{Fe}(\mathrm{OH})^{2+}$ is the dominant species in the aqueous solution from $\mathrm{pH} 2.5$ to 5 [14], and the wavelength of UV radiation from 290 to $400 \mathrm{~nm}$ will photolysis $\mathrm{Fe}(\mathrm{OH})^{2+}$ to produce $\mathrm{Fe}^{2+}$ and hydroxyl radical based on the charge transfer band of $\mathrm{Fe}(\mathrm{OH})^{2+}$ as indicated in Eq. (3). Besides, according to the study of Pignatello [27], degradation of organic compound by $\mathrm{Fe}^{3+} / \mathrm{H}_{2} \mathrm{O}_{2}$ was imposingly accelerated by irradiation with light wavelength above $300 \mathrm{~nm}$. Therefore, the wavelength of UV radiation utilized in this study must be during the range from 300 to $400 \mathrm{~nm}$. In general, the most easily available UV lamps with the maximum emitting wavelength during the range from 300 to $400 \mathrm{~nm}$ are 312 and $360 \mathrm{~nm}$. Furthermore, Pignatello [27] also indicated that radiation wavelength at $312 \mathrm{~nm}$

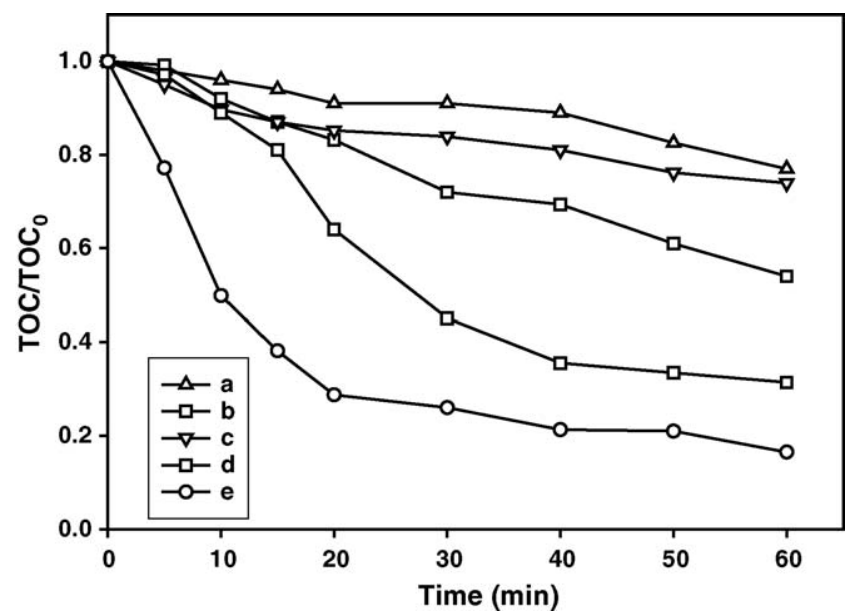

Fig. 3. Dependence of mineralization of DBP on time at various conditions. Experimental conditions: (case a) $\mathrm{UV}\left(\lambda_{312}\right)=120 \mu \mathrm{W} \mathrm{cm}{ }^{-2}, \mathrm{~d}_{\mathrm{H}_{2} \mathrm{O}_{2}} / \mathrm{d} t=$ $3.15 \times 10^{-5} \mathrm{~mol} \mathrm{~min}^{-1} \mathrm{~L}^{-1}$; (case b) $\mathrm{UV}\left(\lambda_{312}\right)=120 \mu \mathrm{W} \mathrm{cm}{ }^{-2}, C_{\mathrm{Fe}^{3+}, 0}=$ $3.60 \times 10^{-4} \mathrm{molL}^{-1} ; \quad$ (case c) $\mathrm{d} C_{\mathrm{H}_{2} \mathrm{O}_{2}} / \mathrm{d} t=3.15 \times 10^{-5} \mathrm{~mol} \mathrm{~min}^{-1} \mathrm{~L}^{-1}$, $C_{\mathrm{Fe}^{3+}, 0}=3.60 \times 10^{-4} \mathrm{~mol} \mathrm{~L}^{-1} ; \quad\left(\right.$ case d) $\mathrm{UV} \quad\left(\lambda_{312}\right)=60 \mu \mathrm{W} \mathrm{cm}^{-2}$, $\mathrm{d} C_{\mathrm{H}_{2} \mathrm{O}_{2}} / \mathrm{d} t=3.15 \times 10^{-5} \mathrm{~mol} \mathrm{~min}^{-1} \mathrm{~L}^{-1}, \quad C_{\mathrm{Fe}^{3+}, 0}=3.60 \times 10^{-4} \mathrm{~mol} \mathrm{~L}^{-1}$; (case e) $\mathrm{UV}\left(\lambda_{312}\right)=120 \mu \mathrm{W} \mathrm{cm}{ }^{-2}, \mathrm{~d}_{\mathrm{H}_{2} \mathrm{O}_{2}} / \mathrm{d} t=3.15 \times 10^{-5} \mathrm{~mol} \mathrm{~min}^{-1} \mathrm{~L}^{-1}$, $C_{\mathrm{Fe}^{3+}, 0}=3.60 \times 10^{-4} \mathrm{~mol} \mathrm{~L}^{-1}$. The other conditions are $C_{\mathrm{DBP} 0}=5 \mathrm{mg} \mathrm{L}^{-1}$, $T=298 \mathrm{~K}$ and $\mathrm{pH} 3.0$.

obtained higher quantum yield than $360 \mathrm{~nm}$. Moreover, the direct photolysis of $\mathrm{H}_{2} \mathrm{O}_{2}$ generates ${ }^{\bullet} \mathrm{OH}$ according to Eq. (5) which requires UV radiation wavelength $<360 \mathrm{~nm}$ [28]. Therefore, UV radiation wavelength at $312 \mathrm{~nm}$ was investigated in this study.

Fig. 3 presents $\eta_{\text {TOC,DBP }}$ as a function of time depending on the various conditions. The $\eta_{\text {TOC,DBP }}$ of the cases ( $\mathrm{a}$ and $\mathrm{b}$ ) in Fig. 3 were $22.3 \%$ and $26.1 \%$, respectively, in 60 min reaction time $(t)$ only with sole $\mathrm{H}_{2} \mathrm{O}_{2}$ or $\mathrm{Fe}^{3+}$ under $\mathrm{UV}$ irradiation (denoted as $\mathrm{UV} / \mathrm{H}_{2} \mathrm{O}_{2}$ and $\mathrm{UV} / \mathrm{Fe}^{3+}$ ). Though the hydroxyl radical could be formed from Eqs. (5), and (3) by UV irradiation, respectively, but the ineffective $\eta_{\text {TOC,DBP }}$ might be attributed to the low amount of ${ }^{\bullet} \mathrm{OH}$ production from these equations, and the extremely chemical stability of DBP.

The case (c) in Fig. 3 presented the mineralization of DBP with adding $\mathrm{Fe}^{3+}$ and $\mathrm{H}_{2} \mathrm{O}_{2}$ but without $\mathrm{UV}$ irradiation, denoted as $\mathrm{H}_{2} \mathrm{O}_{2} / \mathrm{Fe}^{3+}$, revealing $\eta_{\text {TOC,DBP of }} 46 \%$ at $t=60 \mathrm{~min}$. It is apparent that the mineralization of DBP was achieved by $\mathrm{HO}^{\bullet}$ and $\mathrm{HO}_{2}{ }^{\bullet}$ produced from the interaction between $\mathrm{Fe}^{3+}$ and $\mathrm{H}_{2} \mathrm{O}_{2}$. From Eq. (2), $\mathrm{HO}_{2}{ }^{\bullet}$ and $\mathrm{Fe}^{2+}$ could be generated and the generated $\mathrm{Fe}^{2+}$ could be utilized to proceed Eq. (1) and produced $\mathrm{HO}^{\bullet}$ resulting a better mineralization efficiency than the cases ( $a$ and $b$ ) in Fig. 3.

Finally, the cases (d and e) in Fig. 3 illustrated the mineralization of DBP by photo-Fenton reaction, $\mathrm{UV} / \mathrm{H}_{2} \mathrm{O}_{2} / \mathrm{Fe}^{3+}$, under different light intensities with the values of $\eta_{\text {TOC,DBP }}$ as $69.6 \%$ and $76.5 \%$ at $t=60 \mathrm{~min}$, respectively. The experimental results showed that the introduction of UV radiation results in the more effective effect on the enhancement of $\eta_{\text {TOC,DBP }}$ compared with the cases $(a-c)$ in Fig. 3. Furthermore, the stronger light intensity causes higher mineralization efficiency. The improvement of the mineralization efficiency in the $\mathrm{UV} / \mathrm{H}_{2} \mathrm{O}_{2} / \mathrm{Fe}^{3+}$ 
process is significant by the photo-reduction of $\mathrm{Fe}^{3+}$ to $\mathrm{Fe}^{2+}$, which could react with $\mathrm{H}_{2} \mathrm{O}_{2}$ establishing a cycle mechanism of generating hydroxyl radicals. As a result, the mineralization efficiency of DBP under various conditions followed the sequence: $\mathrm{UV}\left(120 \mu \mathrm{W} \mathrm{cm}{ }^{-2}\right) / \mathrm{H}_{2} \mathrm{O}_{2} / \mathrm{Fe}^{3+}>\mathrm{UV}\left(60 \mu \mathrm{W} \mathrm{cm}{ }^{-2}\right) / \mathrm{H}_{2} \mathrm{O}_{2} / \mathrm{Fe}^{3+}$ $>\mathrm{H}_{2} \mathrm{O}_{2} / \mathrm{Fe}^{3+}>\mathrm{UV}\left(120 \mu \mathrm{W} \mathrm{cm}{ }^{-2}\right) / \mathrm{Fe}^{3+}>\mathrm{UV}\left(120 \mu \mathrm{W} \mathrm{cm}{ }^{-2}\right) /$ $\mathrm{H}_{2} \mathrm{O}_{2}$ with the constant dosage rate of $\mathrm{H}_{2} \mathrm{O}_{2}$ at $3.15 \times$ $10^{-5} \mathrm{~mol} \mathrm{~min}^{-1} \mathrm{~L}^{-1}$ and the initial loading concentration of $\mathrm{Fe}^{3+}$ of $3.60 \times 10^{-4} \mathrm{~mol} \mathrm{~L}^{-1}$.

\subsection{Effects of $\mathrm{H}_{2} \mathrm{O}_{2}$ and $\mathrm{Fe}^{3+}$}

The previous works $[29,30]$ reported that there should have an appropriate ratio of $\mathrm{H}_{2} \mathrm{O}_{2}$ to $\mathrm{Fe}^{2+}$ to achieve the optimal treatment efficiency on the organic compounds. However, the optimal ratio depends on the characteristics of the organics. The photoFenton process in this study, $\mathrm{Fe}^{2+}$ was supplied by the photolysis of $\mathrm{Fe}^{3+}$-hydroxyl complex with a constant rate. Hence, a properly continuous addition of $\mathrm{H}_{2} \mathrm{O}_{2}$ is required to maintain an adequate ratio of $\mathrm{H}_{2} \mathrm{O}_{2} / \mathrm{Fe}^{2+}$ for processing Eq. (1) with the supplement of $\mathrm{Fe}^{2+}$ from the photolysis of $\mathrm{Fe}^{3+}-$ hydroxyl complex.

The effect of initial loading concentrations of $\mathrm{Fe}^{3+}\left(C_{\mathrm{Fe}^{3+}, 0}\right)$ on the mineralization of DBP was shown in Fig. 4. The results revealed that a larger $C_{\mathrm{Fe}^{3+}, 0}$ up to $4.50 \times 10^{-4} \mathrm{~mol} \mathrm{~L}^{-1}$ generally gave a higher $\eta_{\text {TOC,DBP }}$ due to the higher aqueous $\mathrm{Fe}^{2+}$ concentration from the photolysis of $\mathrm{Fe}(\mathrm{OH})^{2+}$ which primarily increases with increasing the initial concentration of $\mathrm{Fe}^{3+}$. A higher $C_{\mathrm{Fe}^{3+}, 0}$ can produce more $\mathrm{Fe}^{2+}$ via Eq. (3) and then bring more hydroxyl radicals for the mineralization of DBP via Eq. (1). However, when the $C_{\mathrm{Fe}^{3+}, 0}$ increased higher than $4.50 \times 10^{-4} \mathrm{~mol} \mathrm{~L}^{-1}$, the $\eta_{\mathrm{TOC}, \mathrm{DBP}}$ would become lower. It is because that the ${ }^{\bullet} \mathrm{OH}$ and ${ }^{\bullet} \mathrm{O}_{2} \mathrm{H}$ in the solution would be consumed by the excess $\mathrm{Fe}^{3+}$ and $\mathrm{Fe}^{2+}$ in the solution as indicated in Eqs. (7) and (8) [22], leading the lower photo-Fenton oxidation

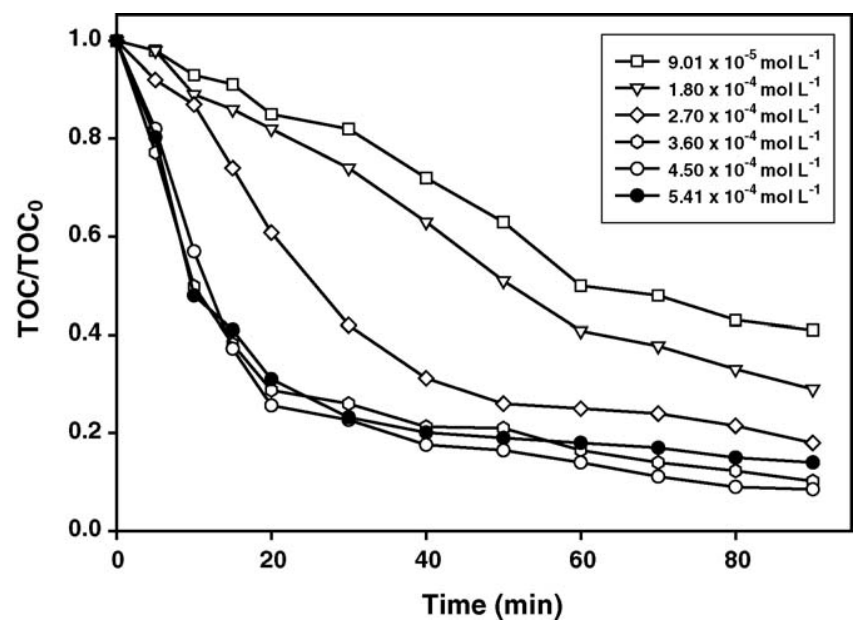

Fig. 4. Time variation of mineralization of DBP at various $C_{\mathrm{Fe}^{3+}, 0}$. Experimental conditions: $\mathrm{UV}\left(\lambda_{312}\right)=120 \mu \mathrm{W} \mathrm{cm}{ }^{-2}, C_{\mathrm{DBP} 0}=5 \mathrm{mg} \mathrm{L}^{-1}$, dosing rate of $\mathrm{H}_{2} \mathrm{O}_{2}\left(\mathrm{~d} C_{\mathrm{H}_{2} \mathrm{O}_{2}} / \mathrm{d} t\right)=3.15 \times 10^{-5} \mathrm{~mol} \mathrm{~min}^{-1} \mathrm{~L}^{-1}, T=298 \mathrm{~K}$ and $\mathrm{pH} 3.0$.

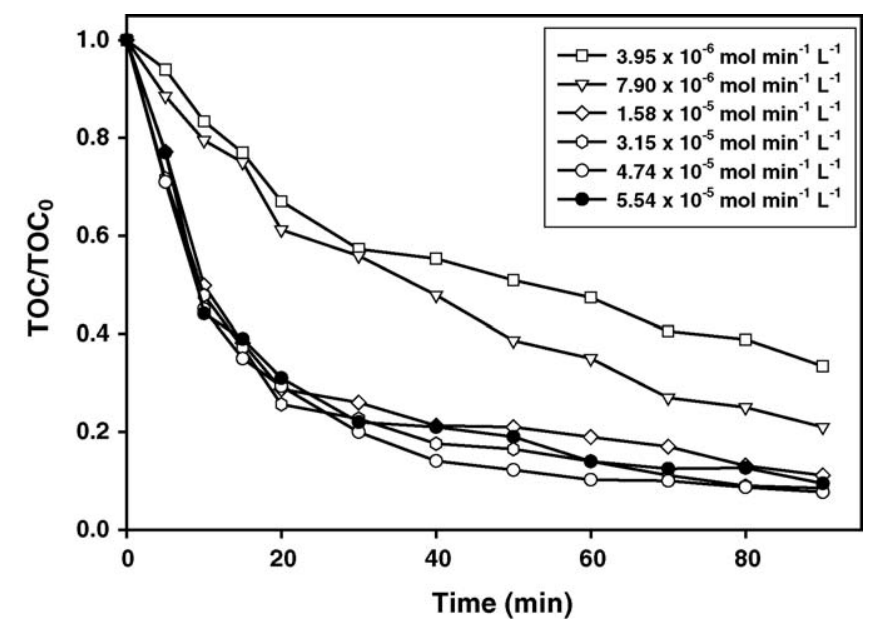

Fig. 5. Dependence of mineralization of DBP on time at various $\mathrm{H}_{2} \mathrm{O}_{2}$ dosing rates $\left(\mathrm{d}_{\mathrm{H}_{2} \mathrm{O}_{2}} / \mathrm{d} t\right)$. Experimental conditions: $\mathrm{UV}\left(\lambda_{312}\right)=120 \mu \mathrm{W} \mathrm{cm}{ }^{-2}$, $C_{\mathrm{DBP} 0}=5 \mathrm{mg} \mathrm{L}^{-1}, C_{\mathrm{Fe}^{3+}, 0}=4.50 \times 10^{-4} \mathrm{~mol} \mathrm{~L}^{-1}, T=298 \mathrm{~K}$ and $\mathrm{pH} 3.0$.

efficiency:

$\mathrm{Fe}^{2+}+\bullet \mathrm{OH} \rightarrow \mathrm{Fe}^{3+}+\mathrm{OH}^{-}, \quad k_{3}=4.3 \times 10^{8} \mathrm{M}^{-1} \mathrm{~s}^{-1}$

$\mathrm{Fe}^{3+}+\mathrm{HO}_{2}^{\bullet} \rightarrow \mathrm{Fe}^{2+}+\mathrm{O}_{2}+\mathrm{H}^{+}, \quad k_{5}=1.0 \times 10^{4} \mathrm{M}^{-1} \mathrm{~s}^{-1}$

The effect of various dosing rates of $\mathrm{H}_{2} \mathrm{O}_{2}\left(\mathrm{~d}_{\mathrm{H}_{2} \mathrm{O}_{2}} / \mathrm{d} t\right)$ on $\eta_{\text {TOC,DBP }}$ was shown in Fig. 5. At higher $\mathrm{H}_{2} \mathrm{O}_{2}$ concentrations, the production of ${ }^{\bullet} \mathrm{OH}$ would increase being beneficial to the mineralization of DBP. $\eta_{\mathrm{TOC}, \mathrm{DBP}}$ increased with increasing $\mathrm{d} C_{\mathrm{H}_{2} \mathrm{O}_{2}} / \mathrm{d} t$ from $3.95 \times 10^{-6}$ to $4.74 \times 10^{-5} \mathrm{~mol} \mathrm{~min}^{-1} \mathrm{~L}^{-1}$ but then decreased when the value of $\mathrm{d} C_{\mathrm{H}_{2} \mathrm{O}_{2}} / \mathrm{d} t$ was greater than $4.74 \times 10^{-5} \mathrm{~mol} \mathrm{~min}^{-1} \mathrm{~L}^{-1}$. Note that the reaction rate constant between $\mathrm{H}_{2} \mathrm{O}_{2}$ and $\bullet \mathrm{OH}$ as Eq. (9) [31] is as high as $2.7 \times 10^{7} \mathrm{M}^{-1} \mathrm{~s}^{-1}$.

$\mathrm{H}_{2} \mathrm{O}_{2}+\bullet{ }^{\bullet} \mathrm{OH} \rightarrow \mathrm{H}_{2} \mathrm{O}+\mathrm{HO}_{2}^{\bullet}, \quad k_{5}=2.7 \times 10^{7} \mathrm{M}^{-1} \mathrm{~s}^{-1}$

Thus, the reaction via Eq. (9) becomes the predominant reaction in comparison with the reaction between ${ }^{\circ} \mathrm{OH}$ and DBP in the condition of excess $\mathrm{H}_{2} \mathrm{O}_{2}$. Hence, the excess concentration of $\mathrm{H}_{2} \mathrm{O}_{2}$ being as the scavenger for the ${ }^{\bullet} \mathrm{OH}$ would reduce the mineralization efficiency. As indicated in this study, the optimal operation conditions for the mineralization of DBP are $\mathrm{d}_{\mathrm{H}_{2} \mathrm{O}_{2}} / \mathrm{d} t$ of $4.74 \times 10^{-5} \mathrm{~mol} \mathrm{~min}^{-1} \mathrm{~L}^{-1}$ and $C_{\mathrm{Fe}^{3+}, 0}$ of $4.50 \times 10^{-4} \mathrm{~mol} \mathrm{~L}^{-1}$ in the solution at $\mathrm{pH} 3.0$ based on the experimental results.

\subsection{Kinetic studies of DBP mineralization}

The reaction kinetics of a photo-Fenton reaction on the mineralization of DBP via UV irradiation with $\mathrm{H}_{2} \mathrm{O}_{2} / \mathrm{Fe}^{3+}$ can be described as:

$\frac{\mathrm{d} C}{\mathrm{~d} t}=-k C^{m}$ 
where $C, m, t$, and $k$ represent the TOC concentration of the DBP solution, order of the reaction, time, and reaction rate constant, respectively. For a second-order reaction, Eq. (10) becomes:

$\frac{1}{C}=\frac{1}{C_{0}}+k t$

where $C_{0}$ is the initial TOC concentration of the DBP solution.

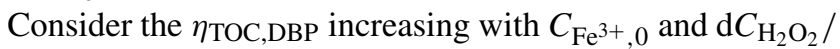
$\mathrm{d} t$ with the range of $9.01 \times 10^{-5}$ to $4.50 \times 10^{-4} \mathrm{~mol} \mathrm{~L}^{-1}$ and $3.95 \times 10^{-6}$ to $4.74 \times 10^{-5} \mathrm{~mol} \mathrm{~min}^{-1} \mathrm{~L}^{-1}$ as shown in Figs. 4 and 5, respectively. Fig. 6(a) shows the plots at various $C_{\mathrm{Fe}^{3+}, 0}$ with $\mathrm{d} C_{\mathrm{H}_{2} \mathrm{O}_{2}} / \mathrm{d} t$ of $3.15 \times 10^{-5} \mathrm{~mol} \mathrm{~min}^{-1} \mathrm{~L}^{-1}$. Fig. 6(b) presents the plots at various $\mathrm{d}_{\mathrm{H}_{2} \mathrm{O}_{2}} / \mathrm{d} t$ for the solution at $C_{\mathrm{Fe}^{3+}, 0}=4.50 \times 10^{-4} \mathrm{~mol} \mathrm{~L}^{-1}$. The results revealed reasonably good linear fits based on the second-order kinetic model as Eq. (11).

The slope associated with the $k$ value varying with $\mathrm{d}_{\mathrm{H}_{2} \mathrm{O}_{2}} / \mathrm{d} t$ and $C_{\mathrm{Fe}^{3+}, 0}$ in Fig. 6 can be further illustrated in Fig. 7. The linear relationships of $\ln k$ with $\ln C_{\mathrm{Fe}^{3+, 0}}$ and $\left(\ln \left(\mathrm{d}_{\mathrm{H}_{2} \mathrm{O}_{2}} / \mathrm{d} t\right)\right)$
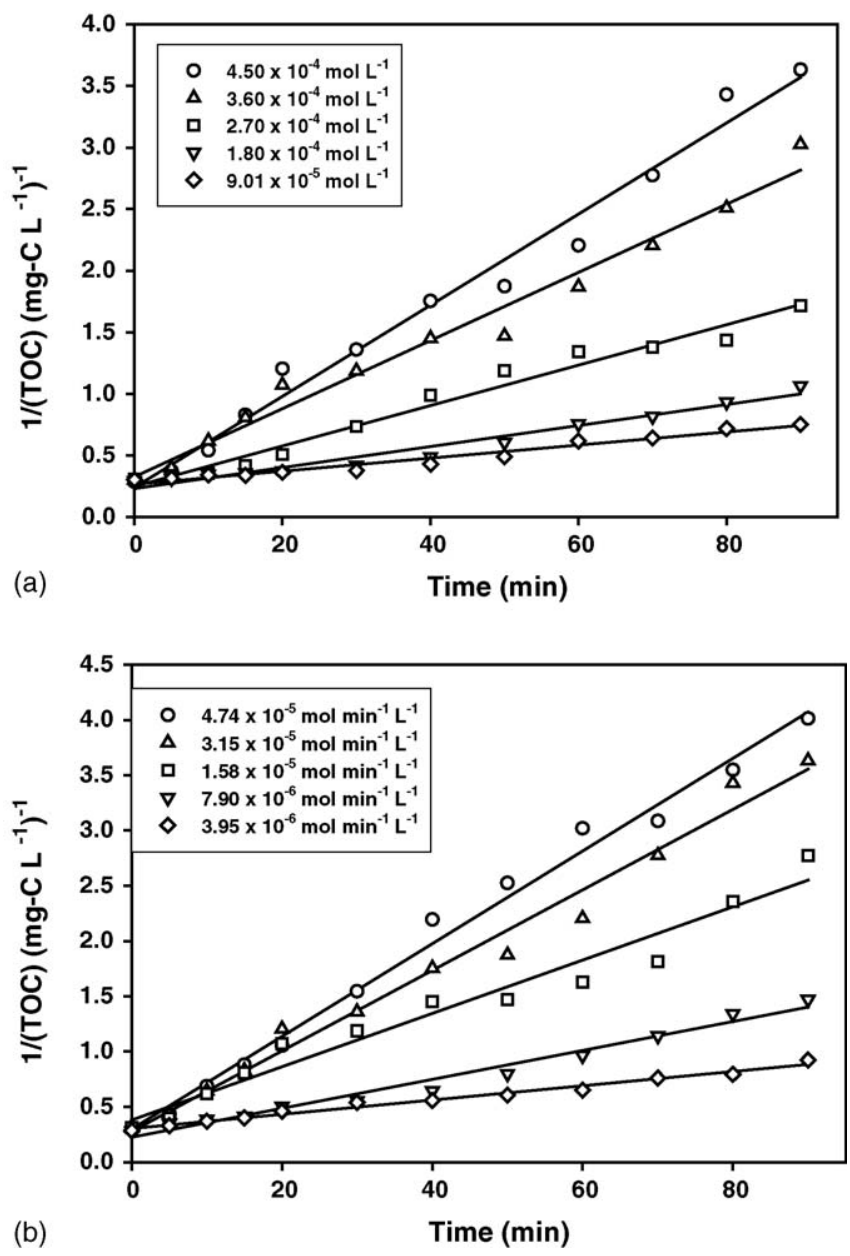

Fig. 6. Analysis of mineralization kinetics of DBP simulated by second-order reaction. (a) Cases with various BOF slag loadings $\left(C_{\mathrm{Fe}^{3+}, 0}\right)$ at a constant $\mathrm{H}_{2} \mathrm{O}_{2}$ dosing rate of $3.15 \times 10^{-5} \mathrm{~mol} \mathrm{~min}^{-1} \mathrm{~L}^{-1}$. The values of $r^{2}$ of regression lines of $\bigcirc, \Delta, \square, \nabla, \diamond: 0.978,0.952,0.942,0.966,0.963$. (b) Cases with various $\mathrm{H}_{2} \mathrm{O}_{2}$ dosing rates at a constant $C_{\mathrm{Fe}^{3+}, 0}=4.50 \times 10^{-4} \mathrm{~mol} \mathrm{~L}^{-1}$. The values of $r^{2}$ of regression lines of $\bigcirc, \triangle, \square, \nabla, \diamond: 0.982,0.984,0.906,0.940,0.984$.
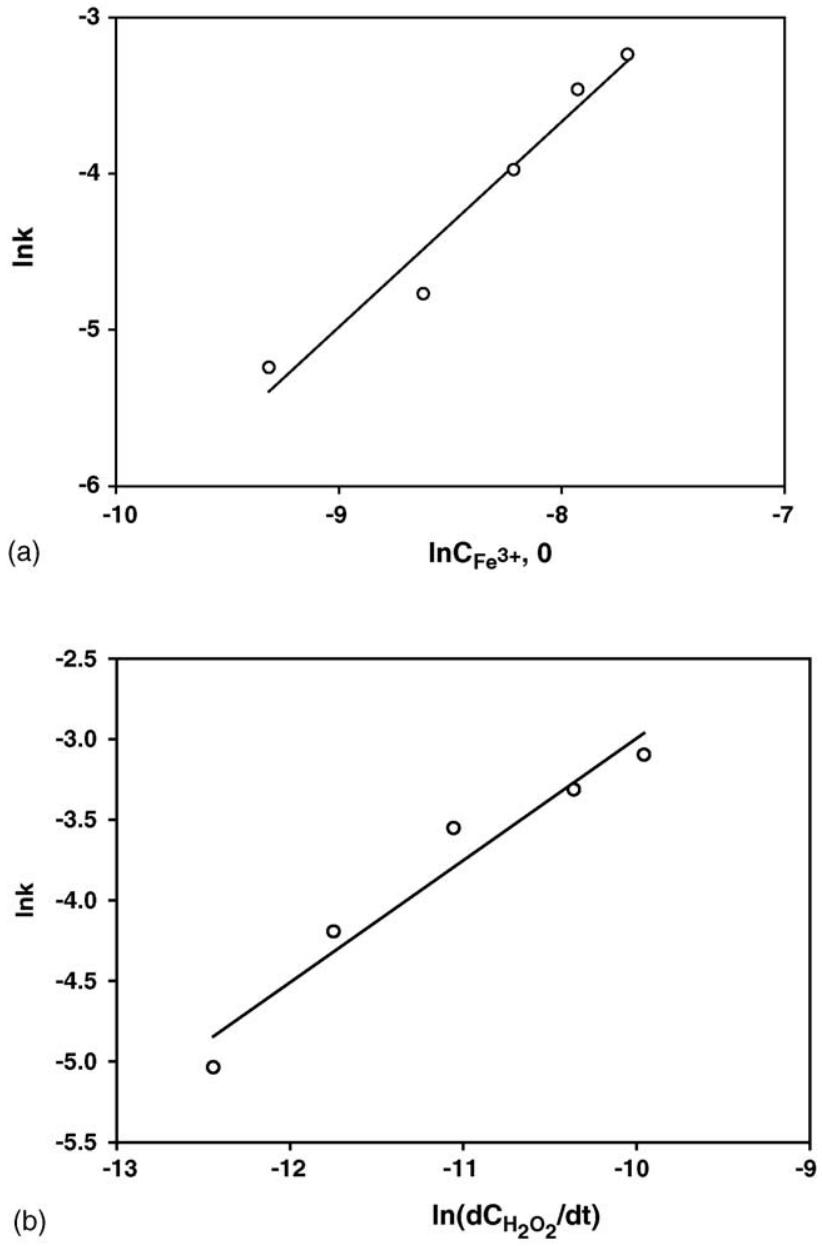

Fig. 7. The relationship between $k$ with $C_{\mathrm{Fe}^{3+}, 0}$ and $\mathrm{d}_{\mathrm{H}_{2} \mathrm{O}_{2}} / \mathrm{d}$ t. Experimental conditions: $\mathrm{UV}\left(\lambda_{312}\right)=120 \mu \mathrm{W} \mathrm{cm}{ }^{-2}, T=298 \mathrm{~K}, \mathrm{pH} 3.0$. (a) $\ln k$ vs. $\ln C_{\mathrm{Fe}^{3+}, 0}$ at a constant $\mathrm{d} C_{\mathrm{H}_{2} \mathrm{O}_{2}} / \mathrm{d} t=3.15 \times 10^{-5} \mathrm{~mol} \mathrm{~min}^{-1} \mathrm{~L}^{-1}, r^{2}=0.959$. (b) $\ln k$ vs. $\ln \mathrm{d} C_{\mathrm{H}_{2} \mathrm{O}_{2}} / \mathrm{d} t$ at a constant $C_{\mathrm{Fe}^{3+}, 0}=4.50 \times 10^{-4} \mathrm{~mol} \mathrm{~L}^{-1}, r^{2}=0.947$. Units of $k, \mathrm{~d} C_{\mathrm{H}_{2} \mathrm{O}_{2}} / \mathrm{d} t, C_{\mathrm{Fe}^{3+}, 0}$ are in $\left(\mathrm{mg}-\mathrm{CL} \mathrm{L}^{-1}\right)^{-1} \mathrm{~min}^{-1}, \mathrm{~mol} \mathrm{~min}^{-1} \mathrm{~L}^{-1}, \mathrm{~mol} \mathrm{~L}^{-1}$, respectively.

then gave the following correlation:

$k=k_{0}\left(C_{\mathrm{Fe}^{3+}, 0}\right)^{x}\left(\frac{\mathrm{d} C_{\mathrm{H}_{2} \mathrm{O}_{2}}}{\mathrm{~d} t}\right)^{y}$

In Eq. (12), $C_{\mathrm{Fe}^{3+}, 0}, \mathrm{~d} C_{\mathrm{H}_{2} \mathrm{O}_{2}} / \mathrm{d} t, x$, and $y$ are the initial loading concentration of $\mathrm{Fe}^{3+}\left(\mathrm{mol} \mathrm{L}^{-1}\right)$, molar dosing rate of $\mathrm{H}_{2} \mathrm{O}_{2}$ (mol min ${ }^{-1} \mathrm{~L}^{-1}$ ), orders of concentration dependence of $C_{\mathrm{Fe}^{3+}, 0}$ and $\mathrm{d}_{\mathrm{H}_{2} \mathrm{O}_{2}} / \mathrm{d} t$, respectively. The values of $x$ and $y$ obtained from the slopes of Fig. 7(a and b) were 1.29 and 0.76, respectively. As a result, the $k_{0}$ in Eq. (12) can be obtained by plotting the obtained $k$ against $\left(C_{\mathrm{Fe}^{3+}, 0}\right)^{1.29} \mathrm{~d}\left(C_{\mathrm{H}_{2} \mathrm{O}_{2}} / \mathrm{d} t\right)^{0.76}$, and then gives $k_{0}$ of $2.01 \times 10^{6}\left(\left(\mathrm{mg}-\mathrm{CL}^{-1}\right)^{-1} \mathrm{~min}^{-1}\right)\left(\mathrm{mol}-\mathrm{Fe}^{3+} \mathrm{L}^{-1}\right)^{-1.29}$ $\left(\mathrm{mol}-\mathrm{H}_{2} \mathrm{O}_{2} \min ^{-1} \mathrm{~L}^{-1}\right)^{-0.76}$ at $298 \mathrm{~K}$.

\section{Conclusions}

The major results of applying $\mathrm{UV} / \mathrm{H}_{2} \mathrm{O}_{2} / \mathrm{Fe}^{3+}$ process to mineralize DBP can be summarized as follows: 
1. The rank of treatment conditions based on the mineralization efficiency of DBP has the sequence: $\mathrm{UV}\left(120 \mu \mathrm{W} \mathrm{cm}{ }^{-2}\right) / \mathrm{H}_{2} \mathrm{O}_{2} / \mathrm{Fe}^{3+}>\mathrm{UV}\left(60 \mu \mathrm{W} \mathrm{cm}{ }^{-2}\right) / \mathrm{H}_{2} \mathrm{O}_{2} /$ $\mathrm{Fe}^{3+}>\mathrm{H}_{2} \mathrm{O}_{2} / \mathrm{Fe}^{3+}>\mathrm{UV}\left(120 \mu \mathrm{Wcm} \mathrm{cm}^{-2}\right) / \mathrm{Fe}^{3+}>\mathrm{UV}(120 \mu$ $\left.\mathrm{W} \mathrm{cm}{ }^{-2}\right) / \mathrm{H}_{2} \mathrm{O}_{2}$.

2. The experimental results in this study suggest that the condition with the UV irradiation $120 \mu \mathrm{W} \mathrm{cm}^{-2} \mathrm{UV}(312 \mathrm{~nm})$, $\mathrm{H}_{2} \mathrm{O}_{2}$ dosages of $4.74 \times 10^{-5} \mathrm{~mol} \mathrm{~min}^{-1} \mathrm{~L}^{-1}$, and initial loading concentration of $\mathrm{Fe}^{3+}$ of $4.50 \times 10^{-4} \mathrm{~mol} \mathrm{~L}^{-1}$ in the solution at $\mathrm{pH} 3.0$ provides the optimal operation performance for the mineralization of DBP $\left(5 \mathrm{mg} \mathrm{L}^{-1}\right)$ of $92.4 \%$ at $90 \mathrm{~min}$ reaction time.

3. The observed experimental data showed a reasonably good expression of the second-order kinetic model with respect to $\mathrm{DBP}$ in terms of TOC: $\mathrm{d} C / \mathrm{d} t=-k C^{2}$. The reaction rate of mineralization of $\mathrm{DBP}$ in terms of TOC $(k)$ can be further correlated to the molar dosing rate of $\mathrm{H}_{2} \mathrm{O}_{2}$ and initial loading concentration of $\mathrm{Fe}^{3+}$ by power expressions, yielding $k\left(\left(\mathrm{mg}-\mathrm{CL}^{-1}\right)^{-1} \min ^{-1}\right)=$ $2.01 \times 10^{6}\left(C_{\mathrm{Fe}^{3+, 0}}\right)^{1.29}\left(\mathrm{~d} C_{\mathrm{H}_{2} \mathrm{O}_{2}} / \mathrm{d} t\right)^{0.76}$ where the units of $C_{\mathrm{Fe}^{3+}, 0}$ and $\mathrm{d}_{\mathrm{H}_{2} \mathrm{O}_{2}} / \mathrm{d} t$ are in $\mathrm{molL}^{-1}$ and $\mathrm{mol} \mathrm{min}^{-1} \mathrm{~L}^{-1}$, respectively.

\section{References}

[1] D.B. Peakall, Phthalate esters: occurrence and biological effects, Res. Rev. 54 (1975) 1-41.

[2] United States Environmental Protection Agency, Fate of priority pollutants in publicly owned treatment works, Final Report, EPA 440/1$82 / 303$.

[3] B.V. Chang, C.S. Liao, S.Y. Yuan, Anaerobic degradation of diethyl phthalate, di- $n$-butyl phthalate, and di-(2-ethylhexyl) phthalate from river sediment in Taiwan, Chemosphere 58 (2005) 1601-1607.

[4] A.C. Staple, D.R. Peterson, T.H. Parkerton, W.J. Adams, The environmental fate of phthalic esters: a literature review, Chemosphere 35 (1997) 667-749

[5] D.R. Shelton, S.A. Boyd, J.M. Tiedije, Anaerobic biodegradation of phthalic acid esters in sludge, Environ. Sci. Technol. 18 (1984) 93-97.

[6] X. Huang, X.J. Zhang, Q. Fu, Assessment for biodegradability of organics in municipal wastewater and controlling measure for its refractory organics, Chin. J. Environ. Sci. 15 (1994) 15-19.

[7] C. Walling, Fenton's reagent revisited, Acc. Chem. Res. 8 (1975) $125-131$.

[8] J.K. Saxe, H.E. Allen, G.R. Nicol, Fenton oxidation of polycyclic aromatic hydrocarbons after surfactant-enhanced soil washing, Environ. Eng. Sci. 17 (2000) 233-244.

[9] F.J. Rivas, F.T. Beltran, J. Frades, P. Buxeda, Oxidation of phydroxybenzoic acid by Fenton's reagent, Water Res. 35 (2001) 387-396.

[10] Q. Wang, A.T. Lemley, Kinetic model and optimization of 2,4-D degradation by anodic Fenton treatment, Environ. Sci. Technol. 35 (2001) 4509-4514.

[11] R. Chen, J.J. Pignatello, Role of quinone intermediates as electron shuttles in Fenton and photoassisted oxidation of aromatic compounds, Environ. Sci. Technol. 31 (1997) 1862-1867.
[12] J. Feng, X. Hu, P.L. Yue, H.Y. Zhu, G.Q. Lu, Discoloration and mineralization of reactive red HE-3B by heterogeneous photo-Fenton reaction, Water Res. 37 (2003) 3776-3784.

[13] M.J. Liou, M.C. Lu, J.N. Chen, Oxidation of TNT by photo-Fenton process, Chemosphere 57 (2004) 1107-1114.

[14] F. Wu, N. Deng, Photochemistry of hydrolytic iron(III) species and photoinduced degradation of organic compounds: a minireview, Chemosphere 41 (2000) 1137-1147.

[15] L.C. Lei, X.J. Hu, P.L. Yue, S.H. Bossmann, S. Göb, A.M. Braun, Oxidative degradation of polyvinyl alcohol by the photochemically enhanced Fenton reaction, J. Photochem. Photobiol. A Chem. 116 (1998) 159166

[16] M. Ravina, L. Campanella, J. Kiwi, Accelerated mineralization of the drug diclofenac via Fenton reactions in a concentric photo-reactor, Water Res. 36 (2002) 3553-3560.

[17] J. Kiwi, C. Pulgarin, P. Peringer, Effect of Fenton and photo-Fenton reactions on the degradation and biodegradability of 2 and 4-nitrophenols in water treatment, Appl. Catal. B Environ. 3 (1994) 335-350.

[18] M.Y. Ghaly, G. Hartel, R. Mayer, R. Haseneder, Photochemical oxidation of $p$-chlorophenol by $\mathrm{UV} / \mathrm{H}_{2} \mathrm{O}_{2}$ and photo-Fenton process: a comparative study, Waste Manage. 21 (2001) 41-47.

[19] X.K. Zhao, G.P. Yang, Y.J. Wang, X.C. Gao, Photochemical degradation of dimethyl phthalate by Fenton reagent, J. Photochem. Photobiol. A Chem. 161 (2004) 215-220.

[20] O. Bajt, G. Mailhot, M. Bolte, Degradation of dibutyl phthalate by homogeneous photocatalysis with $\mathrm{Fe}(\mathrm{III})$ in aqueous solution, Appl. Catal. B Environ. 33 (2001) 239-248.

[21] D.L. Sedlak, A.W. Andren, Oxidation of chlorobenzene with Fenton's reagent, Environ. Sci. Technol. 25 (1991) 777-782.

[22] Z. Wanpeng, Y. Zhihua, W. Li, Application of ferrous-hydrogen peroxide for the treatment of $\mathrm{h}$-acid manufacturing process wastewater, Water Res. 30 (1996) 2949-2954.

[23] S.H. Lin, C.C. Lo, Fenton process for treatment of desizing wastewater, Water Res. 31 (1997) 2050-2056.

[24] B.N. Kwon, D.S. Lee, N. Kang, J. Yoon, Characteristics of pchlorophenol oxidation by Fenton's reagent, Water Res. 33 (1999) 2110-2168.

[25] H.J. Benkelberg, P. Warneck, Photodecomposition of iron(III) hydroxo and sulfato complexes in aqueous solution: wavelength dependence of $\mathrm{OH}$ and $\mathrm{SO}_{4}{ }^{-}$quantum yields, J. Phys. Chem. 99 (1995) 52145221.

[26] V.A. Nadtochenko, J. Kiwi, Photolysis of $\mathrm{FeOH}^{2+}$ and $\mathrm{FeCl}^{2+}$ in aqueous solution, photodissociation kinetics and quantum yields, Inorg. Chem. 37 (1998) 5233-5238.

[27] J.J. Plgnatello, Dark and photoassisted $\mathrm{Fe}^{3+}$-catalyzed degradation of chlorophenoxy herbicides by hydrogen peroxide, Environ. Sci. Technol. 26 (1992) 944-951.

[28] T.M. El-Morsi, M.M. Emara, H.M.H. Abd El Bary, A.S. Abd-El-Aziz, K.J. Friesen, Homogeneous degradation of 1,2,9,10-tetrachlorodecane in aqueous solutions using hydrogen peroxide, iron and UV light, Chemosphere 47 (2002) 343-348.

[29] W.Z. Tang, C.P. Huang, An oxidation kinetic model of unsaturated chlorinated aliphatic compounds by Fenton's reagent, J. Environ. Sci. Health A 31 (1996) 2755-2775.

[30] W.Z. Tang, S. Tassos, Oxidation kinetic and mechanisms by Fenton's reagent, Water Res. 31 (1997) 1117-1125.

[31] G.V. Buxton, C.L. Greenstock, W.P. Helman, A.B. Ross, Critical review of rate constants for reactions of hydrated electrons, hydrogen atoms and hydroxyl radicals $\left({ }^{\bullet} \mathrm{OH} /{ }^{\bullet} \mathrm{O}^{-}\right)$in aqueous solution, J. Phys. Chem. Data 17 (1988) 513-531. 